\title{
Development and validation of the Korean version of the Female Sexual Function Index-5 (FSFI-5)
}

\author{
Seung Jun Chung ${ }^{1}$, Dong-Ouk Yang ${ }^{2,3}$, Ho Song Yu ${ }^{1}$, Kwangsung Park ${ }^{1,2^{*}}$ \\ ${ }^{1}$ Department of Urology, Chonnam National University Medical School, Gwangju, Korea \\ ${ }^{2}$ Sexual Medicine Research Center, Chonnam National University, Gwangju, Korea \\ ${ }^{3}$ Department of Psychology, Chonnam National University, Gwangju, Korea
}

\section{ABSTRACT}

Aims: This study aimed to develop an abbreviated Korean version of the Female Sexual Function Index (FSFI) to provide a rapid screening tool for female sexual dysfunction (FSD) based on the FSFI-19.

Materials and Methods: From the 19 items on the Korean version of the FSFI questionnaire, 5 items representing sexual desire, arousal, lubrication, orgasm, and satisfaction were selected to make the FSFI-5. We interviewed and administered the FSFI-19 and FSFI-5 questionnaires to healthy volunteer women.

Results: A total of 197 subjects were evaluated on two subsequent visits and 89 (45\%) were found to have FSD. The receiver operating characteristic (ROC) curves of the FSFI-5 showed that subjects who scored $\leq 18$ were classified as having FSD. Using the cutoff value of 18 , the sensitivity and specificity of the test were 0.917 and 0.921 , respectively. The area under the ROC curve of the FSFI-5 was 0.973 .

Conclusion: The Korean version of FSFI-5 was developed and validated. It may be a useful tool for screening women with female sexual dysfunction.

Keywords: Spinal cord injuries; Sexual dysfunction; Quality of life

\section{Introduction}

The reported prevalence rate of female sexual dysfunction (FSD) varies widely from $19 \%$ to $45 \%$ depending on the definition of FSD used and the age groups reported (1-4). Evaluation of sexual dysfunction greatly depends on patient self-reporting.

A variety of assessment tools are currently available to help screen and assess FSD. Among these, the Female Sexual Function Index (FSFI) is the most widely used questionnaire (5). The FSFI consists of 19 items distributed across 6 domains, including desire, arousal, lubrication, orgasm, satisfaction, and pain. The FSFI-19 has been translated into Korean, and its reliability and validity have been verified (6). Although it is one of the most useful and meaningful assessment tools for the diagnosis and treatment of FSD, patients may feel uncomfortable and reluctant to complete the 19-item-long questionnaire in public (7-9). To address the issue of length, Isidori et al developed the FSFI-6, which sim-

Manuscript received March 10, 2019; Accepted April 1, 2019.

This study was supported by a grant (CRI13904-21.3) from Chonnam National University Hospital Biomedical Research Institute.

*Corresponding author: Kwangsung Park. Department of Urology, Chonnam National University Medical School, 8 Hakdong, Donggu, Gwangju 61469, Korea.

Tel: +82-62-220-6701, Fax: +82-62-227-1643, E-mail: uropark@gmail.com

(C) Copyright 2019 Korean Association for Sexology

This is an Open Access article distributed under the terms of the Creative Commons Attribution Non-Commercial License (http://creativecommons.org/licenses/by-nc/4.0/)

which permits unrestricted non-commercial use, distribution, and reproduction in any medium, provided the original work is properly cited. 
plified the FSFI by including a single question for each of the six domains (10). Naturally, the FSFI-6 offers the advantages of conciseness and speed (requiring less than 3 minutes to complete).

Because each domain of FSD has various symptoms with complex pathogenesis, the larger disorder category was recently divided into female sexual interest/arousal disorder, female orgasmic disorder, and genito-pelvic pain/penetration disorder (11-14).

In the current study, we selected five of the six domains in the FSFI (desire, arousal, lubrication, orgasm, and satisfaction), excluding the pain domain, to develop and validate the FSFI-5 as a rapid screening tool for female sexual disorder.

\section{Materials and Methods}

\section{Subjects and study design}

We interviewed and administered the FSFI-19 and FSFI-5 questionnaires to healthy volunteer women. A total of 220 married women were recruited to participate in the study. The inclusion criteria required that volunteers agree to complete all questionnaires, have no active infection, and have been in a stable sexual relationship with a male partner for at least the past 6 months.

Initially, all subjects completed the full-length FSFI-19 and the FSFI-5. According to the international cutoff value, participants with an FSFI-19 score $<26.55$ were classified in the "female sexual dysfunction" group. After 3 weeks, all participants were asked to complete the FSFI-5 and FSFI-19, respectively. This study was approved by IRB of the Chonnam National University Hospital (CNUH-2013-154).

\section{Female Sexual Function Index (FSFI-5)}

We excluded the "pain" domain from the FSFI-19 and made the FSFI-5, which consisted of item-by-item com- binations of the five domains of sexual "desire", "arousal", "lubrication", "orgasm", and "satisfaction". Representative items of each domain were selected from the FSFI-19 by referring to the FSFI-6 (Appendix 1).

\section{Statistical analysis}

PASW Statistics for Windows, version 18.0 was used to assess the validity of the FSFI-5. Basic data were obtained by using mean values \pm standard deviations. Receiver operating characteristic (ROC) analysis was performed, and Cronbach's alpha was calculated to verify the internal consistency of the tool. To obtain the test-retest reliability of the two questionnaires, the Pearson correlation coefficient was calculated by using the results of two rounds of questionnaires. For validity analysis, a cutoff score was obtained with optimal sensitivity and specificity required to screen individuals with sexual dysfunction.

\section{Results}

\section{Characteristics of the study population}

Of the initial 220 participants, 197 were finally enrolled in this study. Three women (1.4\%) did not complete the questionnaires and were excluded from the study population. Twenty women $(9.1 \%)$ were eliminated for having no sexual activity during the previous 4 weeks.

Table 1 shows the characteristics of the study population. The mean age of the enrolled volunteers was $35.93 \pm 4.26$ years (range: 25 to 50 years) and the mean body mass index (BMI) was $21.15 \pm 2.04 \mathrm{~kg} / \mathrm{m}^{2}$. A total of 5 women (2.5\%) had hypertension, 3 (1.5\%) had diabetes mellitus, $10(5.1 \%)$ had a personal history of reproductive system diseases (uterus, ovaries, etc), and 4 (2.0\%) were current smokers.

\section{Comparison between FSD and non-FSD groups}

Of the 197 final participants, 89 with an FSFI-19 score 
Table 1. Baseline characteristics of the study population

\begin{tabular}{|c|c|}
\hline & Total $(n=197)$ \\
\hline Age (years, range: 25-50) & $35.93 \pm 4.26$ \\
\hline $\mathrm{BMI}\left(\mathrm{kg} / \mathrm{m}^{2}\right)$ & $21.15 \pm 2.04$ \\
\hline Marriage duration (years) & $7.07 \pm 4.05$ \\
\hline Intercourse number (during last 4 weeks) & $5.64 \pm 1.66$ \\
\hline \multicolumn{2}{|l|}{ Underlying disease $(n)$} \\
\hline Hypertension & 5 \\
\hline Diabetes mellitus & 3 \\
\hline Hepatitis history & 1 \\
\hline Thyroid disease & 1 \\
\hline \multicolumn{2}{|l|}{ Reproductive system disease (n) } \\
\hline Uterine myoma & 7 \\
\hline Pelvic inflammatory disorder & 1 \\
\hline Ovarian disease & 2 \\
\hline Current smoker (n) & 4 \\
\hline \multicolumn{2}{|l|}{ Menopause status [n (\%)] } \\
\hline Yes & $56(28.4 \%)$ \\
\hline No & $141(71.6 \%)$ \\
\hline \multicolumn{2}{|l|}{ Group [n (\%)] } \\
\hline Non-FSD (FSFI-19>26.55) & $108(54.8 \%)$ \\
\hline FSD (FSFI-19<26.55) & $89(45.2 \%)$ \\
\hline
\end{tabular}

BMI, body mass index; FSFI, Female Sexual Function Index; FSD, female sexual dysfunction.

<26.55 points were classified into the FSD group. In the comparison of clinical factors between the FSD and non-FSD groups, age $(\mathrm{p}=0.317)$, BMI $(\mathrm{p}=0.220)$, and marriage duration $(\mathrm{p}=0.132)$ showed no significant differences, whereas the participants with FSD had a lower intercourse number during the previous 4 weeks (4.84 \pm 1.31 vs $6.30 \pm 1.78, \mathrm{p}<0.001)$ (Table 2).

\section{Evaluating the $\mathrm{FSFI}-5$}

The score for each item on the FSFI-5 and the total score of the FSFI-5 were significantly lower in the FSD group than in the non-FSD group $(\mathrm{p}<0.001$, Table 2$)$. Fig. 1 shows the ROC curve for the FSFI-5. The estimated area under the ROC curve (AUC) was $0.973(95 \%$ confidence interval: $0.952 \sim 0.993)$. The ROC curve was
Table 2. Comparison between the FSD and Non-FSD groups

\begin{tabular}{lccc}
\hline & FSD $(n=89)$ & $\begin{array}{c}\text { Non-FSD } \\
(n=108)\end{array}$ & p-value \\
\hline $\begin{array}{l}\text { Age (years, range } \\
\text { 25-50) }\end{array}$ & $36.27 \pm 4.36$ & $35.66 \pm 4.18$ & 0.317 \\
BMI (kg/m²) & $21.35 \pm 2.26$ & $20.99 \pm 1.83$ & 0.220 \\
$\begin{array}{l}\text { Marriage duration } \\
\text { (years) }\end{array}$ & $7.55 \pm 3.74$ & $6.68 \pm 4.27$ & 0.132 \\
$\begin{array}{l}\text { Intercourse number } \\
\text { (during last 4 weeks) }\end{array}$ & $4.84 \pm 1.31$ & $6.30 \pm 1.78$ & $<0.001$ \\
FSFI-5 score & $14.57 \pm 2.26$ & $19.78 \pm 1.78$ & $<0.001$ \\
q2 : desire & $2.74 \pm 0.53$ & $3.71 \pm 0.68$ & $<0.001$ \\
q4 : arousal & $2.82 \pm 0.51$ & $3.91 \pm 0.50$ & $<0.001$ \\
q7 : lubrication & $3.15 \pm 0.68$ & $4.04 \pm 0.55$ & $<0.001$ \\
q11 : orgasm & $2.84 \pm 0.74$ & $4.03 \pm 0.57$ & $<0.001$ \\
q16 : satisfaction & $3.02 \pm 0.67$ & $4.09 \pm 0.48$ & $<0.001$ \\
\hline BMI, body mass index; FSFI, Female Sexual Function Index; \\
FSD, female sexual dysfunction..
\end{tabular}

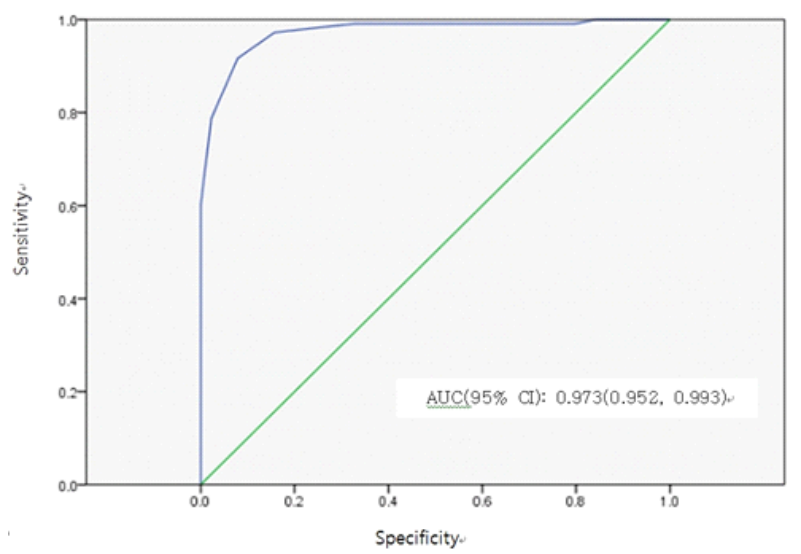

Fig. 1. Receiver operating characteristic (ROC) curve for total score of the Female Sexual Function Index-5 (FSFI-5). AUC, area under the curve.

performed to find the FSFI-5 cutoff value for making a diagnosis of FSD. As shown in Table 3, the sensitivity and specificity of the FSFI-5 were $91.7 \%$ and $92.1 \%$, respectively, at a score of 18 . Women who scored $\langle 18$ were diagnosed as having FSD, whereas those who scored $\geq 18$ were diagnosed as not having FSD.

In the analysis of internal consistency of the FSFI-5, the responses for the five domains showed a strong correlation. Cronbach's alpha was 0.887 , suggesting a very high level of reliability, and the Pearson correlation 
Table 3. Sensitivity and specificity rates and Youden's index for cutoff scores

\begin{tabular}{cccc}
\hline Cutoff score & Sensitivity & Specificity & $\begin{array}{c}\text { * Youden's } \\
\text { index }\end{array}$ \\
\hline 13 & 0.991 & 0.202 & 0.193 \\
14 & 0.991 & 0.258 & 0.249 \\
15 & 0.991 & 0.326 & 0.317 \\
16 & 0.991 & 0.674 & 0.665 \\
17 & 0.972 & 0.843 & 0.815 \\
18 & 0.917 & 0.921 & 0.838 \\
19 & 0.787 & 0.978 & 0.765 \\
20 & 0.602 & 1 & 0.602 \\
\hline
\end{tabular}

* Youden's index $=$ Sensitivity + Specificity -1.

Table 4. Inter-item correlation matrix and Cronbach's alpha

\begin{tabular}{lccccc}
\hline & Desire & Arousal & $\begin{array}{c}\text { Lubrica- } \\
\text { tion }\end{array}$ & Orgasm & $\begin{array}{c}\text { Satisfac- } \\
\text { tion }\end{array}$ \\
\hline Desire & - & 0.588 & 0.519 & 0.567 & 0.540 \\
Arousal & 0.588 & - & 0.449 & 0.645 & 0.528 \\
Lubrication & 0.519 & 0.449 & - & 0.538 & 0.159 \\
Orgasm & 0.567 & 0.645 & 0.538 & - & 0.610 \\
Satisfaction & 0.540 & 0.528 & 0.159 & 0.610 & - \\
\hline
\end{tabular}

Cronbach's alpha $=0.887$; Pearson score $=0.707$.

coefficient was 0.707 (Table 4).

\section{DISCUSSION}

The FSFI is a self-reported, 19-item questionnaire assessing sexual function. It is one of the best tools for diagnosing FSD and for monitoring treatment (15). Because of its usefulness, the FSFI has been used consistently in outpatient clinics, but is sometimes considered too long for routine use. To reduce patient discomfort and to create a rapid screening test for FSD, Isidori et al (10) developed the FSFI-6, an abridged form of the FSFI.

Although the FSFI-19 has six domains for assessing female sexual dysfunction, sexual pain can be associated with infection or inflammation of the vulva or vagina or can be related to psychosexual disorder. Therefore, the sexual pain domain needs to be evaluated separately for the screening of sexual interest/arousal disorder. In the present study, we designed and validated the Korean version of the FSFI-5 as a rapid screening tool for female sexual dysfunction. Additionally, we determined the cutoff score with optimal sensitivity and specificity.

A questionnaire's validity consists of item validity, discriminating power, and linguistic validity. Reliability is assessed with the test-retest reliability index and the internal consistency index of each domain. The reliability and validity of the Korean FSFI were tested and proven previously (6). Because the FSFI-5 is a simplified version of the FSFI, additional verification was deemed unnecessary. Additionally, the selection process for optimal items was waived, because the FSFI- 5 consists of a single item selected from each domain of the FSFI-6 with exclusion of the "pain" domain.

Of 197 survey participants, 89 were suspected to have female sexual dysfunction, yielding a prevalence rate of $45 \%$. The prevalence rate of FSD in our study was higher than reported in other previous studies $(16,17)$. In the current study, individuals with FSFI scores of less than 26.55 points were considered to have sexual dysfunction. This reference point was deduced on the basis of a study by Wiegel et al (18). The sensitivity and specificity of the Korean FSFI-5 were assessed on the basis of this reference point, and the optimal cutoff score was suggested on the basis of the ROC curve. Whereas the current study determined an FSFI score of 26.55 to be an acceptable cutoff, a Turkish study by Oksuz et al (19) assessed a prevalence rate using a cutoff score of 25 points. The prevalence rates of the current study and a study by Song et al (17) are similar, at $42.9 \%$ and $43.1 \%$ respectively. However, Oksuz et al reported a higher prevalence rate of $48.3 \%$. This discrepancy may be due to sociocultural and linguistic differences between the two countries.

In this study, Cronbach's alpha, which evaluates the 
internal consistency level of each domain in the female sexual dysfunction questionnaire, was relatively high at 0.887. The intraclass correlation coefficient, which measures test-retest reliability, was also high, at 0.816 . However, the Pearson correlation coefficient between the first and second rounds of the survey was 0.707 , lower than in previous results. It is also worth noting that most of the eliminated participants reported no sexual activity for 4 weeks in response to one the questionnaires. This implies changes in sexual activity patterns during the 3 weeks between the test and the retest. The same issue has been reported in the other studies, which prompted a modification to the Japanese version from "the past 4 weeks" to "the past 3 months" (20). Nevertheless, the relatively low Pearson correlation coefficient still exceeds 0.7 (a standard required for group questionnaires) (21) and therefore satisfies the original intent of the questionnaire.

The FSFI-6, a simplified version of the FSFI, offers the advantages of convenience and speed because it takes less than 3 minutes to complete (22). The FSFI-5 has the same advantages. The Cronbach's alpha of the FSFI-5 was 0.887 , which is higher than that of the FSFI-6 (10). The reliability of the FSFI- 5 was higher than that of the FSFI- 6 because the pain domain showed a weak indirect correlation in the FSFI-6. The AUC of the FSFI-5 was 0.973 (0.952-0.993), which did not differ greatly from the AUC of $0.984(0.951-0.997)$ of the FSFI-6. A study by Lee et al (11) found the Cronbach's alpha and AUC of the FSFI-6K to be 0.888 and $0.948(0.92-0.976)$, respectively, similar to the results of our study. Therefore, the reliability analysis indicates that the FSFI- 5 has sufficient reliability as a tool for screening of FSD.

The current study had limitations. First, the participants were limited to relatively young women residing in the local area. Therefore, the prevalence rate in this study cannot be generalized across the female population in Korea. Second, we did not evaluate the effect of the pain domain. Future study is needed to compare the FSFI-6 and the FSFI-5 in women with FSD.

In conclusion, the current study developed and verified the FSFI-5, which is based on the Korean version of the FSFI. The questionnaire's internal consistency showed high reliability, and the reliability correlation coefficient was statistically significant. Therefore, the FSFI- 5 may be a useful tool to screen Korean women with female sexual disorder. Further research is needed to evaluate the role of the pain domain, which was not included in the FSFI-5.

\section{ORCID}

Kwangsung Park https://orcid.org/0000-0001-8827-162X

\section{References}

1. Laumann EO, Palik A, Rosen RC. Sexual dysfunction in the United States: prevalence and predictors. JAMA 1999;281:537-44.

2. Lindau ST, Schumm LP, Laumann EO, Levinson W, O'Muircheartaigh CA, Waite LJ. A study of sexuality and health among older adults in the Unites States. N Engl Med 2007;357:762-74.

3. Hayes RD, Dennerstein L, Bennett CM, Fairley CK. What is the "true" prevalence of female sexual dysfunctions and dose the way we assess these conditions have an impact? J Sex Med 2008;5:777-87.

4. Palacios S, Castano R, Grazziotin A. Epidemiology of female sexual dysfunction. Maturitas 2009;63:119-23.

5. Keskin U, Coksuer H, Gungor S, Ercan CM, Karasahin $\mathrm{KE}$, Baser I. Differences in prevalence of sexual dysfunction between primary and secondary infertile women. Fertil Steril 2011;96:1213-7.

6. Kim HY, So HS, Park KS, Jeong SJ, Lee JY, Ryu SB. Development of the Korean-version of Female Sexual 
Function Index (FSFI). Korean J Androl 2002;20:50-6.

7. Basson R, Berman J, Burnett A, Derogatis L, Ferguson D,

Fourcroy J, et al. Report of the international consensus development conference on female sexual dysfunction: definitions and classifications. J Urol 2000;163:888-93.

8. Geiss IM, Umek WH, Dungl A, Sam C, Riss P, Hanzal E. Prevalence of female sexual dysfunction in gynecologic and urogynecologic patients according to the international consensus classification. Urology 2003;62:514-8.

9. Phillips NA. Female sexual dysfunction: evaluation and treatment. Am Fam Physician 2000;62:127-36.

10. Isidori AM, Pozza C, Esposito K, Giugliano D, Morano S, Vignozzi L, et al. Development and validation of a 6-item version of the female sexual function index (FSFI) as a diagnostic tool for female sexual dysfunction. J Sex Med 2010;7:1139-46.

11. Basson R. On the definition of female sexual interest/arousal disorder. Arch Sex Behav 2014;43:1225-6.

12. Balon R, Clayton AH. Female sexual interest/arousal disorder: a diagnosis out of thin air. Arch Sex Behav 2014;43:1227-9.

13. Laan E, Rellini AH, Barnes T. Standard operating procedures for female orgasmic disorder: consensus of the International Society for Sexual Medicine. J Sex Med 2013;10:74-82.

14. Lahaie MA, Amsel R, Khalife S, Boyer S, FaaborgAndersen M, Binik YM. Can fear, pain, and muscle tension discriminate vaginismus from dyspareunia/provoked vestibulodynia? Implications for the new DSM-5 diagnosis of genito-pelvic pain/penetration disorder. Arch Sex Behav 2015;44:1537-50.

15. Meston CM. Validation of the Female Sexual Function Index (FSFI) in women with female orgasmic disorder and in women with hypoactive sexual desire disorder. J Sex Marital Ther 2003;29:39-46.

16. Lee Y, Lim MC, Son Y, Joo J, Park K, Kim JS, et al. Development and evaluation of Korean version of Quality of Sexual Function (QSF-K) in healthy Korean women. J Korean Med Sci 2014;29:758-63.

17. Song SH, Jeon H, Kim SW, Paick JS, Son H. The prevalence and risk factors of female sexual dysfunction in young Korean women: an internet-based survey. J Sex Med 2008;5:1694-701.

18. Wiegel M, Meston C, Rosen R. The female sexual func-

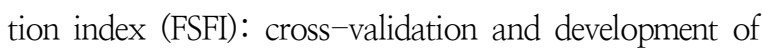
clinical cutoff scores. J Sex Martial Ther 2005;31:1-20.

19. Oksuz E, Malhan S. Prevalence and risk factors for female sexual dysfunction in Turkish women. J Urol 2006;175:654-8.

20. Takahashi M, Inokuchi T, Watanabe C, Saito T, Kai L. The Female Sexual Function Index (FSFI) : development of a Japanese version. J Sex Med 2011;8:2246-54.

21. Tanner CA, Imle M, Stewart B. Guidelines for evaluation of research for use in practice. NLN Publ 1989;(15-2322): 35-60.

22. Cayan S, Akbay E, Bozlu M, Canpolat B, Acar D, Ulusoy E. The prevalence of female sexual dysfunction and $\mathrm{po}^{-}$ tential risk factors that may impair sexual function in Turkish women. Urol Int 2004;72:52-7. 


\section{Appendix}

\section{Appendix 1. 한글판 FSFI-5}

지난 4 주 동안

성욕이나 성적 흥미가 어느 정도였습니까?

성행위(성교 포함)을 하는 동안 성적 흥분은 어느 정도였습니까?

성적 자극이 있거나 성교를 했을 때, 윤활액이 얼마나 자주 분비되었습니까?

성적자극이 있거나 성교를 했을 때, 오르가즘(절정감)을 얼마나 자주

느꼈습니까?

전반적인 성생활에 대해서 얼마나 만족하십니까?
매우 높은 편이었다 높은 편이었다 5

성행위가 없었다 매우 높은 편이다

0

높은 편이다

4

성행위가 없었다

$$
0
$$

항상 분비되었다 5

성행위가 없었다

0

항상 느꼈다

5

대부분 분비되었다

대부분 느꼈다

4

중간 정도이다

매우 만족한다

5
대부분 만족한다
중간 정도이다 3

3

중간 정도였다 3

중간 정도이다 3

낮은 편이다

매우 낮은 편이다 $\begin{array}{cc}\text { 기끔 분비되었다 } & \text { 거의 분비되지 않았다 } \\ 2 & 1\end{array}$

가끔 느꼈다 거의 느끼지 못했다

중간 정도이다 대체로 불만족한다 거의 만족하지 못한다 